\title{
Bochdalek Hernia in Asymptomatic Adults: A Case Report of Radiological Importance
}

\author{
AMAZIZ $^{\mathrm{a}}, \mathrm{R}^{\mathrm{O} A S M I N}{ }^{\mathrm{b}}$, MAHAQUE $^{\mathrm{c}}$
}

\begin{abstract}
Summary:
Congenital Diaphragmatic Hernias $(\mathrm{CDH})$ is a rare entity with incidence of 1:3000 live births. Late presentation is unusual and in most cases is diagnosed in adolescents or early childhood. Asymptomatic diaphragmatic hernia in the absence of trauma is very rare in adults. The finding of $\mathrm{CDH}$ in adults is mostly incidental. Left sided hernia i.e. Bochdalek hernia is more common. It is more commonly associated with other anomalies. The morbidity and mortality are mainly due to pulmonary hypoplasia. We report a case of $\mathrm{CDH}$, posterolateral defect (Bochdalek type), with mild
\end{abstract}

\section{Introduction:}

Congenital Diaphragmatic Hernia (CDH ) is a term applied to a variety of congenital birth defects that involve abnormal development of the diaphragm through which protrusion of abdominal viscera into the chest cavity occur. ${ }^{1} \mathrm{CDH}$ is classified according to the location of the protrusion, including in hiatal hernia, Morgagni-Larrey hernia and Bochdaleck hernia. ${ }^{2}$ Bochdaleck hernia was first described in 1848 by the Czechoslovakian anatomist, Vicent Alexander Bochdalek. ${ }^{3}$ It is a posterior congenital defect of the diaphragm caused by a lack of closure of the pleuroperitoneal cavity between the eighth and tenth week of embryonic life. $70 \%$ to $90 \%$ of cases occur on the left. ${ }^{4}$ It usually presents in childhood with an incidence ranging from 1:4000 to 1:7000 newborns ${ }^{5}$ and more frequent in male. ${ }^{6,7}$ Patients usually presents during the first hours after birth with severe respiratory

a. Dr. Ahmad Monjurul Aziz, Junior Consultant, Dept. of Medicine, Dhaka Dental College Hospital, Dhaka.

b. Dr. Rubina Yasmin, Professor \& Head, Dept. of Medicine, Dhaka Dental College Hospital, Dhaka.

c. Dr. Md. Azharul Haque, Dept. of Medicine, Dhaka Dental College Hospital, Dhaka.

Address of Correspondence: Dr. Ahmad Monjurul Aziz, Junior Consultant, Dept. of Medicine, Dhaka Dental College Hospital, Dhaka. Phone:+8801715040286,E-mail: amaemon@gmail.com

Received: 28 September, 2017

Accepted: 2 June, 2018 mediastinal shifting to right side in a young lady, who was asymptomatic throughout the life and referred to us for evaluation of incidental findings of chest X-ray abnormality who was suffering from cholelithiasis. The surgical approach for the resolution of this pathology is variable and it depends on the presence and severity of visceral complications.

Keywords: Congenital diaphragmatic hernia, Bochdalek hernia, diaphragm.

(J Bangladesh Coll Phys Surg 2018; 36: 175-178) DOI: http://dx.doi.org/10.3329/jbcps.v36i4.38188

failure. ${ }^{8,9}$ It is rarely seen in adults, with little more than 100 cases reported in the literature. ${ }^{10}$ Traumatic diaphragmatic hernia can present in any age group. ${ }^{11}$

Asymptomatic large Bochdalek hernia is quite rare among adults. ${ }^{12}$ These patients usually present with difficulty in breathing or pneumonia like symptoms or gastrointestinal symptoms and end up being diagnosed with $\mathrm{CDH} .{ }^{13} \mathrm{CDH}$ should be included in the differential diagnosis of pneumonia and other respiratory or gastrointestinal diseases. ${ }^{14,15} \mathrm{~A}$ definite diagnosis can be made by $\mathrm{CT}$ alone because of its characteristic features. ${ }^{12}$ Here is a case of an asymptomatic adult with a large left sided Bochdalek hernia.

\section{Case Report:}

A 25 year old housewife hailing from a rural community presented to surgery department for elective cholecystectomy. As a part of pre-operative assessment basic investigations including chest $\mathrm{x}$-ray was done. Then she took subsequent two courses of antibiotics for radiological abnormality in left lung. But her radiological abnormalities didn't improved. Then she was referred to our department for further evaluation of that radiological abnormalities which showed a nonhomogeneous opacity occupying left mid and lower zone with mediastinal shifting was found in the left lung in chest X-ray [Figure-1]. 


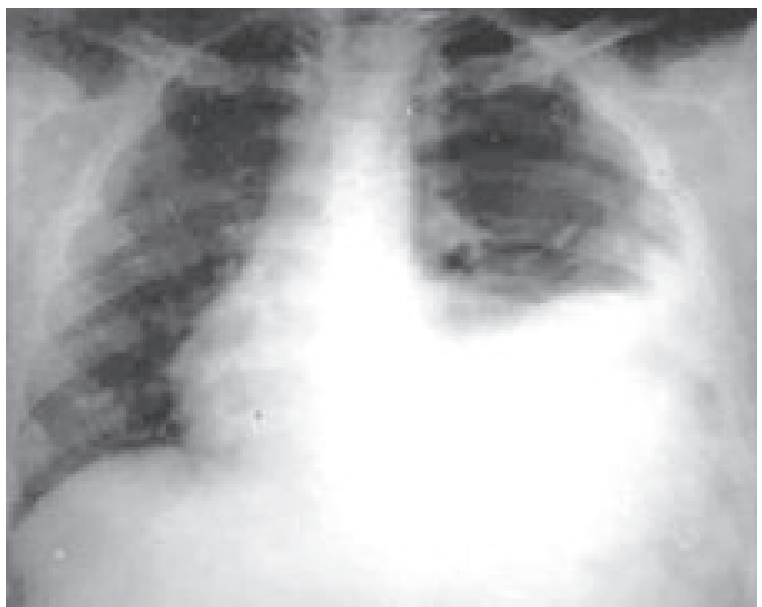

Fig.-1: X-ray Chest Posterior-Anterior view showing nonhomogeneous opacity occupying left mid and lower zone with mediastinal shifting to right side.

On query she denied any respiratory complaints. She had no history of fever, abdominal pain, any bowel abnormality or any other significant symptoms. She had no significant past history suggestive of respiratory disease including tuberculosis. General examination revealed only mild anaemia with normal respiratory rate. Chest examination revealed mildly restricted movement, resonant percussion note with reduced breath sound in left lower zone. Laboratory investigation results showed no abnormalities and ultrasonogram of whole abdomen showed only cholelithiasis.

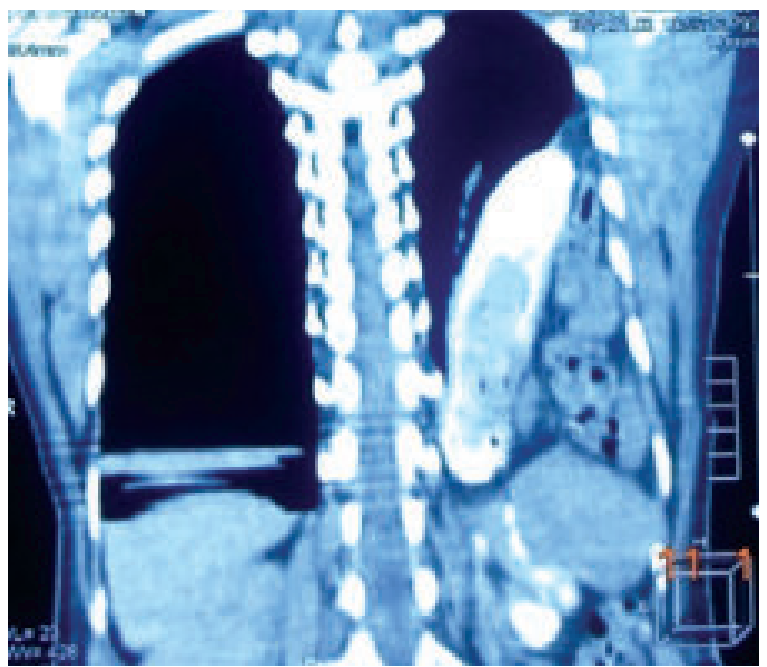

Fig.-3: Computed Tomography of chest with oral contrast showing left hemi-diaphragmatic defect with herniation of stomach and coils of intestine into the thorax.

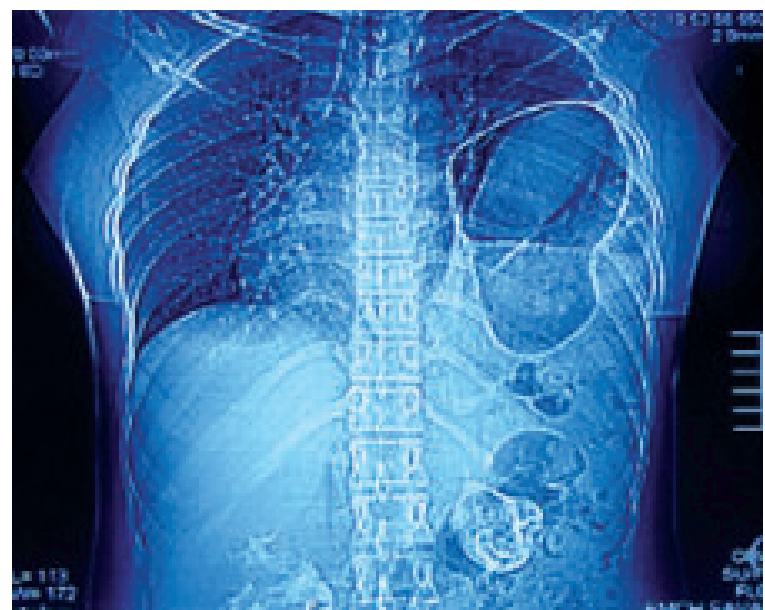

Fig.-2: Computed Tomography of chest showing left hemi-diaphragmatic defect with herniation of stomach and coils of intestine into the thorax, compression of the left lung and mild mediastinal shifting

As she was asymptomatic with normal laboratory investigations and such radiological findings, we further investigate her to find out other possibilities including congenital anomalies.

A CT scan of the chest with abdominal screening was advised. Computed tomography with oral contrast demonstrated a left hemi-diaphragmatic defect with herniation of stomach and coils of intestine into the thorax, compression of the left lung and mild mediastinal shifting suggestive of diaphragmatic herniaBochdalek's. Finally the patient was referred to thoracic surgeon for surgical correction of the defect.

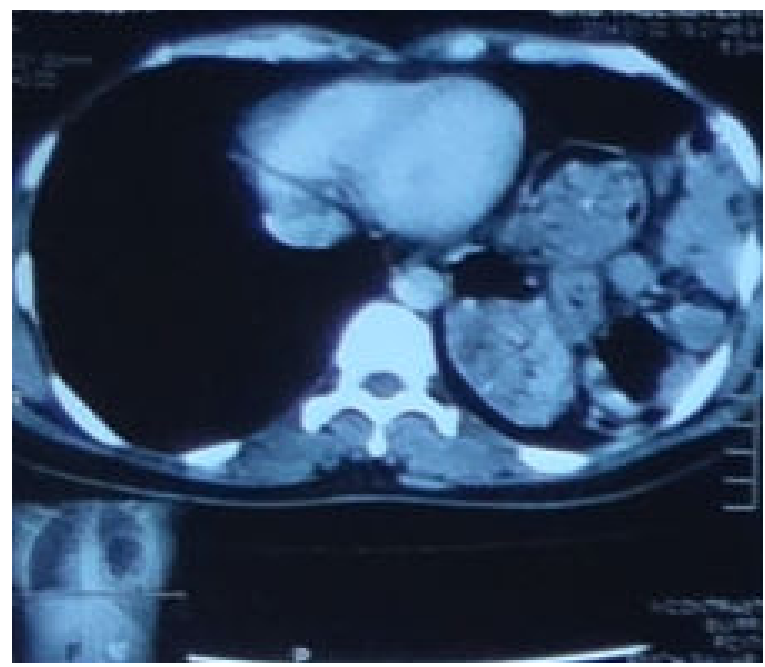

Fig.-4: Computed Tomography of chest showing herniation of stomach and coils of intestine into the left side of chest with mild mediastinal shifting to right side. 


\section{Discussion:}

A Bochdalek hernia is a congenital defect of the diaphragm located in the posterior insertion. This is caused by a lack of closing of the pleuroperitoneal cavity by incomplete diaphragmatic development before the intestine returns to the abdomen from the yolk sack between weeks 8 and 10 of gestation. If hernia formation precedes lung development, pulmonary hypoplasia may occur with severe respiratory compromise at birth. The diaphragmatic defect may be congenital or acquired. The most frequent cause of herniation of the abdominal viscera in adults seems to be trauma (blunt or penetrating) followed by iatrogenic (esophago-gastric surgery for esophagus cancer or gastric cancer). ${ }^{17}$ In adults, this defect is uncommon, the lung in most cases develops normally and therefore symptoms are rare. ${ }^{18}$ The most frequently displaced organ is the stomach followed by the colon, spleen, small intestine and ureter. ${ }^{18,19,20}$

The overall prevalence of asymptomatic $\mathrm{BH}$ in adults is $6 \%$. From all patients with a congenital BH only $5 \%$ will be diagnosed in childhood or adulthood ${ }^{21}$. In 1959 Kirkland published the first review of 34 cases of adult $\mathrm{BH}^{1}$. Adult $\mathrm{BHs}$ can present in two ways. They can give rise to vague, mainly gastrointestinal (abdominal pain, nausea and vomiting, constipation) or respiratory (chest pain, dyspnoea, wheezing) symptoms, followed by severe attacks and episodes of incarceration with serious consequences. Characteristically, these symptoms can be intermittent, as herniated viscera can spontaneously reduce causing symptom regression. Others will present with serious complications associated with strangulation of herniated viscera, especially when the diagnosis has been missed or treatment delayed. There have been reports of $\mathrm{BH}$ presenting with sudden death from intrathoracic complications. Gastric volvulus is one of the rare but recognized complications of $\mathrm{BH}^{21}$

The diagnosis can be achieved through a simple chest $\mathrm{X}$-ray, computerized axial tomography and MRI or an upper gastrointestinal series..$^{22,23,24}$ Typically, radiological images show intra-thoracic gas-filled loops of the bowel with/without mediastinal shifting. In some cases, the herniated bowel loops may be present as an opacity mimicking a lung consolidation. In other cases the gas-filled bowel loops may simulate a pneumothorax. Rarely, the herniated bowel loops may be complicated and present as intestinal obstruction or volvulus. ${ }^{25,26}$ So for these variable presentations, diagnosis of Bochdalek hernia by only X-ray films are not always easy.

A computed tomography (CT) scan is the radiological investigation that allows the highest accuracy for a correct diagnosis. It provides a precise assessment of the anatomical relationships between the viscera, and congenital malformations, as in our cases. The typical findings of the CT scan are the presence of fat or soft tissue over the upper surface of the diaphragm characteristically posterolateral, a mass adjacent to the diaphragmatic defect, and a continuous density over and under the diaphragm's discontinuity. ${ }^{24}$

In our case a left hemi-diaphragmatic defect with herniation of stomach and coils of intestine into the thorax, compression of the left lung and mild mediastinal shifting was observed. The principal management of Bochdalek hernias include reducing the abdominal organs and repairing the defect. The surgical approach for this pathology depends on the presence of visceral complications. In an elective setting most authors recommend the thoracic approach; on the other hand, when there are septic complications, the abdominal approach is preferred. The current trend is to use minimal invasive surgical techniques such as laparoscopy, and specially thoracoscopy, which has been satisfactorily performed in adults. ${ }^{9,27-29}$

Very few cases of delayed presentation of $\mathrm{CDH}$ in asymptomatic adults are described in the literature. We report a case of asymptomatic adult patient who was referred to us for the evaluation of persistent left lung opacity on chest X-ray. Computed tomography of the lung confirmed the diagnosis of diaphragmatic hernia. The aim of this case report is to aware the clinicians regarding evaluation of causes of asymptomatic lung shadow on chest X-ray in adults, diaphragmatic hernia should be a consideration.

\section{Conclusion:}

Bochdalek hernias are an uncommon diagnosis among adult populations because they are mainly recognized in infancy or early childhood. They can be easily documented with a chest X-ray or CT thorax, in most cases incidentally although some adult patients may present with symptoms due to hernia complications. 
Hence high index of clinical suspicion and knowledge of this anatomic defect is crucial for the identification and management. It should be surgically corrected to avoid complications. To improve the quality of medical treatment for $\mathrm{CDH}$ in adults, more cases will need to be reported and long-term follow up should proceed.

\section{References:}

1. Gedik E, Tuncer MC, Onat S, AvcI A, TacyIldIz I, Bac B. A review of Morgagni and Bochdalek hernias in adults. Folia Morphol 2011;70(1):5-12. (Internet) [Last accessed on 13 January 2015].Available from http://www. czasopisma.viamedica.pl/fm/ article/download/19322/15215

2. Mandhan P, Memon A, Memon AS: Congenital hernias of the diaphragm in children. Journal of Ayub Medical College, Abbottabad. JAMC 2007, 19:37-41.

3. Puri P, Wester T. Historical aspects of congenital diaphramatic hernia. Pediatr Surg Int 1997;12:95-100.

4. Perch P, Houck W, de Anda A. Symptomatic Bochdalek hernia in an octogenarian. Ann Thorac Surg 2002;73:1288-9.

5. Loch LF: Hérnia diafragmática congênita de apresentação tardia. RevAMRIGS 2008, 52:212-215.

6. Torfs CP, Curry CJ, Bateson TF, Honore LH: A population-based study of congenital diaphragmatic hernia.

7. Yang W, Carmichael SL, Harris JA, Shaw GM: Epidermiologic characteristics of congenital diaphragmatic hernia among 2.5 million California births, 1989-1997.

8. Nieto ZJ, Bracho BE, Godoy Murillo JG, Ortiz de la OE, Delgado GJ. Hernia diafrag-mática congénita posterolateral bilateral. Informe de un caso y revisión de la literatura. Bol Med Hosp Infant Mex 1994;15(1):39-42.

9. Sabiston S. Surgery of the chest. 5th ed. Philadelphia; 1990. p. 957-60.

10. Ruano R: Prenatal diagnosis and perinatal outcome of 38 cases with congenital diaphragmatic hernia: 8-year experience of a tertiary Brazilian center. Clinics 2006, 61:122-127.

11. Rey L: Dicionário de termos técnicos de medicina e saúde. 2nd edition. Rio de Janeiro: Editora Guanabara Koogan S/a; 2003:950.

12. Horton DB, Lieberman G. An Unusual Presentation of Diaphragmatic Hernia. (Internet) [Last accessed on January 2015]. Available from eradiology.bidmc.harvard.edu/Learning Lab/gastro/Horton.pdf

13. Wasey W, Wasey N. Delayed Presentation of Congenital Diaphragmatic Hernia as Heart Failure. JOURNAL OF CASE REPORTS 2014;4(2):291-94. (Internet) [Last accessed on 13
January 2015]. Available from http://www.casereports.in/ printerfriendly.aspx?id=350

14. Berman L, Stringer DA, Ein S, Shandling B: Childhood diaphragmatic hernias presenting after the neonatal period.

15. Fotter R, Schimpl G, Sorantin E, Fritz K, Landler U: Delayed presentation of congenital diaphragmatic hernia. Clin Radiol 1992,22:187-191.

16. Bianchi E, Mancini P, Vito SD, Pompili E, Taurone S, Guerrisi I, et al. Congenital asymptomatic diaphragmatic hernias in adults: a case series. Journal of Medical Case Reports. 2013;7:125. (Internet) [Last accessed on 13 January 2015]. Available from http://www.jmedicalcasereports.com/content/7/1/125

17. Miller BJ, Martin IJ. Bochdalek hernia with hemorrhage in an adult. Can J Surg 1993;36(5):476-8.

18. Steen buis LH, Tjon A, Tham RT, Smeenk FW. Bochdalek hernia; a rare case of pleural empyema. Eur Respir J 1994;7(1):204-6.

19. Chui PP, Tan CT. Sudden death due to incarcerated Bochdalek hernia in an adult. Ann Acad Med Singapore 1993;22(1):57-60.

20. Giannoulis K, Sutton R. Bochdalek hernia presenting in adult life:report of an unusual case and review of the literature. ANNALS OF GASTROENTEROLOGY 2004;17(1):109-12. (Internet) [Last accessed on January 2015]. Available from www.annalsgastro.gr/index.php/annalsgastro/article/download/ $275 / 243$

21. Shin MS, Mulligan SA, Baxley WA, Ho K-J. Bochdalek hernia of diaphragm in the adult. Chest 1987;92:1098.

22. Sugimura A, Kikuchi J, Satoh M, Ogata M, Inoue H, Takishima T. Bilateral Bochdalek hernias in an elderly patient diagnosed by magnetic resonance imag-ing. Intern Med 1992;31:281-3.

23. Gale ME. Bochdalek hernia: prevalence an CT characteristics. Radiology 1985;156:449-52.

24. Lin ST, Moss DM, Henderson SO: A case of Morgagni hernia presenting as pneumonia. JEm Med 1997, 15:297-301.

25. Gayer G, Bilik R, Vardi A: CT diagnosis of delayed presentation of congenital diaphragmatic hernia simulating massive pleuropneumonia. Eur Radiol 1999, 9:1672-1674.

26. Taskin M, Zengin K, Unal E, Eren D, Korman U. Laparoscopic repair of congenital diaphragmatic hernias. Surg Endosc 2002;16:869.

27. Willemse P, Schutte PR, Plaisier PW. Thoracoscopic repair of a Bochdalek hernia in an adult. Surg Endosc 2003;17:162.

28. Silen ML, Canvasser DA, Kurkchubasche AG, Andrus CU, Naunbeim KS. Video-assisted thoracic surgical repair of a foramen Bochdalek hernia. Ann Thorac Surg 1995;60(2):448-50. 